\title{
Air pollution measurements related to urban traffic in Bucharest
}

\author{
Lelia Letitia Popescu ${ }^{1,}$, Razvan Stefan Popescu ${ }^{1}$, Andrei Preda ${ }^{2}$ and Karim Limam ${ }^{3}$ \\ ${ }^{1}$ Technical University of Civil Engineering of Bucharest, Romania \\ ${ }^{2}$ Maritime University of Constanta, Department of General Sciences, Constanta, Romania \\ ${ }^{3}$ La Rochelle University, La Rochelle, France
}

\begin{abstract}
This study is presenting pollution level in Bucharest, the sources being mainly the traffic or vehicles, that became in larger numbers every year. A new mobile laboratory is used which is able to monitor continuously $\mathrm{PM}_{2,5}, \mathrm{PM}_{10}, \mathrm{NO}_{\mathrm{x}}, \mathrm{NO}, \mathrm{NO}_{2}, \mathrm{O}_{3}, \mathrm{CO}, \mathrm{SO}_{2}$ and $\mathrm{BTEX}$. The diurnal variations are presented in different environmental conditions: rainy day and sunny day, to compare the results and to present which is the outdoor influence of meteorological conditions. Particulate matter is influenced by rain as well as other compounds like BTEX. Ozone production is influenced by the solar radiation, so it's also an interesting comparison between the two studied cases. BTEX compounds are measured by a mobile chromatograph placed in the lab and presents for every $30 \mathrm{~min}$. the diurnal variations of toluene, benzene, $\mathrm{m}, \mathrm{p}, \mathrm{o}$ xylene and ethylbenzene.
\end{abstract}

\section{Introduction}

Urban and industrial development, continuously increasing of the number of vehicles, deforestation, are just some few factors which conducted to the actual high levels of atmospheric pollution. In recent decades, a strong correlation indicates the association between high level of air pollution and its effects on human health, such as mortality rates, hospitalization for respiratory problems and cardiovascular diseases, worsening of asthma attacks, low weight newborn, high infant and prenatal mortality, tuberculosis, cataract, nasopharyngeal, larynx and lung cancer [1], [2]. Vehicles with petrol and diesel engines emit a variety of air pollutants, such as: $\mathrm{CO}, \mathrm{NO}_{2}, \mathrm{SO}_{2}$, [3] volatile organic compounds (VOCs) [4], and particulate matter (PM) which have an increasing impact on urban air quality. Adverse effects on health were observed at surprisingly low and relatively common concentrations of particulate pollution. Most of the epidemiological researches had focused on episodic or short term changes in exposures. Few recent studies report that long-term exposure to fine-particulate air pollution may have even larger impacts on cardiopulmonary mortality [5]. Outdoor particle pollution influence indoor air quality as well, as building envelope protection efficiency varies, being strongly affected by materials' ancientness, quality and also work quality [5].
Nitrogen dioxide, one of the main traffic-related air pollutants and precursors forming photochemical smog (together with VOCs) and ground-level ozone, is currently under intensive investigations.

The BTEX (benzene, toluene, ethylbenzene and xylenes) may cause damage to the central nervous system and respiratory, gastrointestinal and reproductive systems; benzene was selected as it is the first known carcinogen [3] to be controlled by a European air quality directive, Directive EU 2008/50 on air pollution for benzene.

The oxidation of toluene and xylenes, in particular, can produce numerous carbonyl compounds, within the atmosphere, in sufficient quantities to ozone production (the photochemical smog) [6].

Benzene is a toxic carcinogen $[7,8]$ and epigenetic modifications were correlated to human exposure to benzene low dose [9]. Toluene is less toxic but produces drowsiness, impaired co-ordination, and liver and kidney damage [10]. Usually, pollutants coexist in the ambient air, several of them may have additive or even synergistic effects. Both benzene and toluene can affect the human central nervous system and they generally coexist with each other in the urban air due to several common resources [11].

The context of the study is to find out filtration solutions for those areas of high pollution areas. There

* Corresponding author: lelialetita@yahoo.com 
are few studies, all of them developed in the past in Romania, concerning pollution levels found in well known key points. There is a close relationship between high pollution levels and human diseases, some of these pollutants being known as carcinogen at certain concentrations in the air. It is well known that there are a lot of European studies upon this subject, one of them being online pollution index which shows that Scandinavian capitals have the lowest levels of pollution (being the "greenest" ones), and at the opposite corner are Bucharest, Kiev, Barcelona, Paris or Rome.

The first stage aims of this project is the pollution levels measurement encountered in a central area of Bucharest. It would be interested to find out if the pollution levels are below legal limits or exceeding these limits. To accomplish this goal the mobile pollution laboratory was used to measure for several days in several places, chosen by their high pollution levels known from monitoring stations which worked in the past. The mobile lab is able to monitor continuously the following compounds: $\mathrm{NO}_{\mathrm{x}}, \mathrm{SO}_{2}, \mathrm{O}_{3}, \mathrm{CO}$, BTEX and particles $\mathrm{PM}_{10}, \mathrm{PM}_{2.5}$. Generally, the determination procedure of BTEX compounds in urban air followed the steps of first pre-concentrated by active or passive sampling, after a thermal desorption and analysis on gas chromatography technique (GC), with FID, PID or MS detectors [7]. In our case the mobile laboratory used in this research was able to measure every $30 \mathrm{~min}$, on site, without any other adjustment, leading finally to more accurate results. The results of the first stage presented hourly variations of pollutants in different measured places showing comparisons between them, and a comparison as a function of weather conditions (rainy days, sunny days, warm or cold days).

The second stage of this research should focus on finding a filtration method which should be able to reduce pollution levels of BTEX, more specifically benzene, toluene, ethylbenzene and xylene and PM. Air purification and filtration are promising approaches that could be used to control the level of pollutants. Adsorption is one of the methods where volatile organic compounds are retained on activated carbon filters. Using this method clean filtered air may be introduced into the buildings in polluted urban areas. The fibrous material named activated carbon is obtained by carbonization, usually from nut shells, coal, peat, wood, at a temperature of $900-1000^{\circ} \mathrm{C}$. Most important parameters which influence adsorption are temperature, solubility, concentration, molecule polarity and bounding energy. In some research studies one can notice that as a function of pollutant type some of the pollutant are adsorbed in few hours, others in few months [12], so it's very important to study the particular behavior of pollutant/activated carbon type.

In this research proposal we started using data from other previous studies which focused on adsorption field, having a good knowledge in this subject [12],[13]. In these research studies, modeling results are compared to experimental data in dry conditions for specific purposes like filtration of indoor air from nuclear submarines, the contaminants being from another origin than fuel combustion (ethanol, toluene, R134a, acetaldehyde, cyclohexane, acetone). Other studies included the influence of humidity, but only based on prediction models and not being compared to experimental data [14]. To study competition between different compounds like MEK and n-hexane there is good agreement in dry and humid conditions between modeling and experimental data [15]. A fan driven air cleaning system reviewed by Zhang [16] concluded that sorption of gaseous pollutants was among the most effective technologies, but insufficient information regarding long term performance and proper maintenance was found in the literature. This is the reason why modeling of activated carbon devices for improving indoor air quality can be found [17]. The results can be used in practical applications for improving Indoor Air Quality by using activated carbon filters.

The novelty of this study is that in a particular place like Bucharest city, with its particular pollutant levels encountered outdoors, the research aims to propose filtration technique adapted to the pollutants existing outside from traffic related combustion. Other studies were interested in different pollutants than BTEX for other filtration purposes. Mainly industrial applications are found in the literature for activated carbon techniques.

\section{Methods used}

For outdoor pollution measurements we used a new type of portable emission measurement system (PEMS). It is widely used for measurements in real time values in different places and for long time measurements. For BTEX determination air used a pre-concentrated probe by active or passive sampling, using adsorption, thermal desorption and following analysis on gas chromatography technique (GC) in this case. The mobile lab has also a meteorological measurement device for temperature, humidity, outdoor pressure, wind direction and wind speed and solar radiation. These data are very important for pollution measurements.

Pollutants measured related to traffic in urban areas are: BTEX, $\mathrm{NO}_{\mathrm{x}}, \mathrm{O}_{3}, \mathrm{SO}_{2}$ and $\mathrm{CO}, \mathrm{PM}_{10}, \mathrm{PM}_{2.5}$, which are continuously measured and also can be monitored and transmitted remotely using IOVIS software. In table 1 , all the devices that are included in the mobile lab are presented along with their specifications. The data presented and stored is guaranteed using periodic calibration of each equipment calibration that is required by the fabricant.

For particle concentrations there are two equipments that have be used: a Portable Environmental Dust Monitor 11-E (manufactured by GRIMM) with a $5 \mathrm{~min}$. time step or any other interval for $\mathrm{PM}_{2,5}$, and particle concentration $\mathrm{PM}_{10}$ was measured using a Verewa device, which cannot measure $\mathrm{PM}_{10}$ and $\mathrm{PM}_{2.5}$ in the same time. 
Table 1. Equipments from the mobile laboratory devices

\begin{tabular}{|l|l|l|l|l|}
\hline Pollutant & Device & $\begin{array}{l}\text { Measurement } \\
\text { principle }\end{array}$ & $\begin{array}{l}\text { Measuring } \\
\text { range }\end{array}$ & $\begin{array}{l}\text { Detection } \\
\text { limit }\end{array}$ \\
\hline BTEX & $\begin{array}{l}\text { GC 5000 } \\
\text { AMA }\end{array}$ & GC/FID & $0-50 \mu \mathrm{g} / \mathrm{m}^{3}$ & $0.03 \mathrm{ppb}$ \\
\hline $\mathbf{N O}_{\mathbf{x}}$ & $\begin{array}{l}\text { APNA } \\
370 \\
\text { Horiba }\end{array}$ & $\begin{array}{l}\text { Chemi- } \\
\text { luminescence }\end{array}$ & $0-1.0 \mathrm{ppm}$ & $0.5 \mathrm{ppb}$ \\
\hline $\mathbf{O}_{3}$ & $\begin{array}{l}\text { APOA } \\
370 \\
\text { Horiba }\end{array}$ & $\begin{array}{l}\text { Ultraviolet } \\
\text { absorption }\end{array}$ & $0-1.0 \mathrm{ppm}$ & $0.5 \mathrm{ppb}$ \\
\hline $\mathbf{C O}$ & $\begin{array}{l}\text { APMA } \\
370 \\
\text { Horiba }\end{array}$ & $\begin{array}{l}\text { Non-dispersive } \\
\text { infrared } \\
\text { absorption }\end{array}$ & $0-100 \mathrm{ppm}$ & $0.05 \mathrm{ppm}$ \\
\hline $\mathbf{S O}_{2}$ & $\begin{array}{l}\text { APSA } \\
370 \\
\text { Horiba }\end{array}$ & $\begin{array}{l}\text { Ultraviolet } \\
\text { fluorescence }\end{array}$ & $00.5 \mathrm{ppm}$ & $0.5 \mathrm{ppb}$ \\
\hline $\mathbf{P M}_{\mathbf{1 0}}$ & $\begin{array}{l}\text { F701-20 } \\
\text { Verewa }\end{array}$ & $\begin{array}{l}\text { Beta radiation } \\
\text { adsorption }\end{array}$ & $0-10 \mathrm{mg} / \mathrm{m}^{3}$ & $\begin{array}{l}0.001 \mathrm{mg} / \mathrm{m} \\
3\end{array}$ \\
\hline $\mathbf{P M}_{2.5}$ & $\begin{array}{l}\text { Dust } \\
\text { Monitor } \\
11-\mathrm{E} \\
\text { Grimm }\end{array}$ & Laser radiation & $0.25-32$ \\
$\mu \mathrm{m}$ & $0.1 \mu \mathrm{g} / \mathrm{m}^{3}$ \\
\hline
\end{tabular}

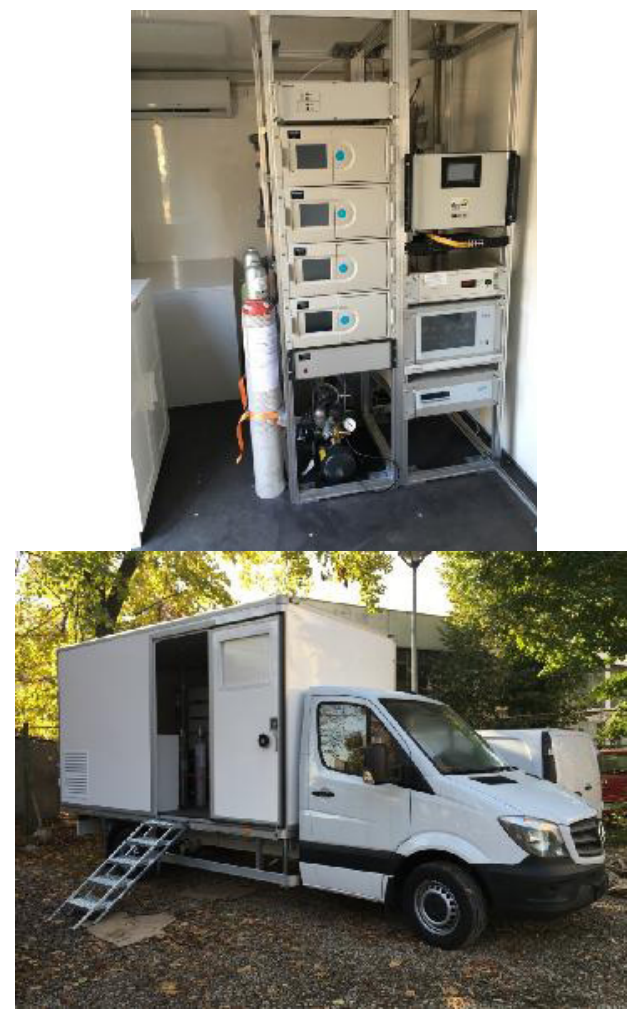

Fig. 1. Photos with the mobile laboratory for outdoor air quality measurements

\section{Results and discussion}

In this study the outdoor air quality levels of pollution are measured. We were interested in investigating the link between outdoor pollution and car traffic, from a crowded street in Bucharest. The mobile laboratory was placed in the Pache Protopopescu 66 Boulevard, the dates for measurements were:

-for the sunny day 11 may 2017;

-for the rainy/cloudy day 7 may 2017.

The measurements presented in figure 2 compared to figure 3 shows a slighter highly value for the sunny day compared to the rainy day, because the rain is cleaning the atmosphere, included the pollutants. In the total VOC we summed all the compounds from BTEX: xylenes, toluene, ethylbenzene and benzene. The two maximum values in the morning and evening are correlated with the peaks in the traffic encountered on that boulevard close to the measuring points.

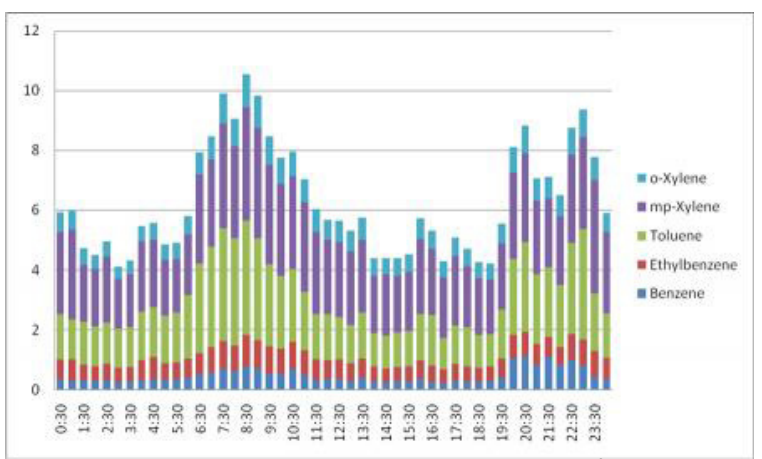

Fig. 2. Total VOC measured in a sunny day, $\mu \mathrm{g} / \mathrm{m}^{3}$

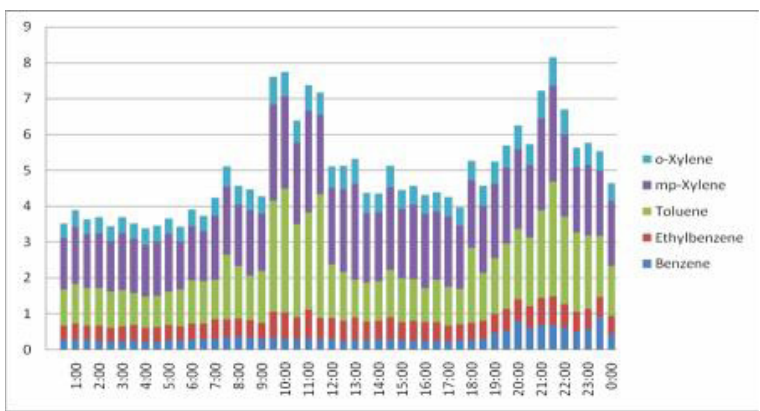

Fig. 3. Total VOC measured in a rainy day, $\mu \mathrm{g} / \mathrm{m}^{3}$

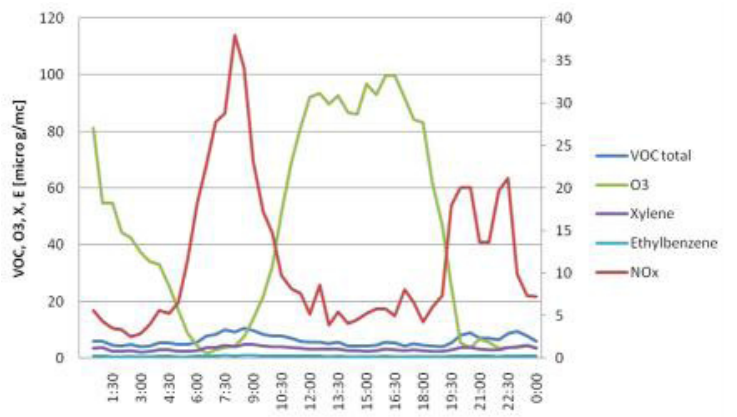

Fig. 4. Total VOC, ozone, xylene, ethylbenzene and $\mathrm{NO}_{\mathrm{x}}$ measured on a sunny day 


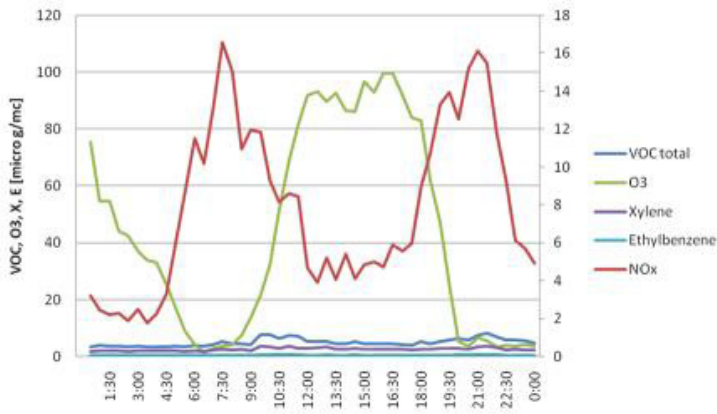

Fig. 5. Total VOC, ozone, xylene, ethylbenzene and $\mathrm{NO}_{\mathrm{x}}$ measured on for the rainy day

In figure 4 it's presented the high concentrations of ozone, which corresponds with low concentrations of $\mathrm{NO}_{\mathrm{x}}$. The production of ozone is due to photochemical reactions in the presence of solar radiation. There is a delay of some few hours between the maximum value of global solar radiation and the high values of ozone concentration (figure 6). Ussually the values for ozone concentration are close to the limit, and sometimes are passing the limit of $120 \mu \mathrm{g} / \mathrm{m}^{3}$.

Comparing figures 4 and figure 5 one can notice a slightly difference for VOCs between the two considered days to be monitored. So, it's not an important influence of the rain over the ozone and $\mathrm{NO}_{\mathrm{x}}$ production.

Comparing figures 6 and figure 7, the production of ozone is influenced by solar radiation, but the maximum value of around $100 \mu \mathrm{g} / \mathrm{m}^{3}$ is still encountered in both days. Solar radiation varies from less than $500 \mathrm{~W} / \mathrm{m}^{2}$ to $1000 \mathrm{~W} / \mathrm{m}^{2}$, as maximum values in these two studied cases. In figure 6 there is a time gap, between the solar radiation and the ozone concentration peak. There are photochemical reactions to produce ozone, influenced by solar radiation, the gap meaning the reaction time of ozone production.

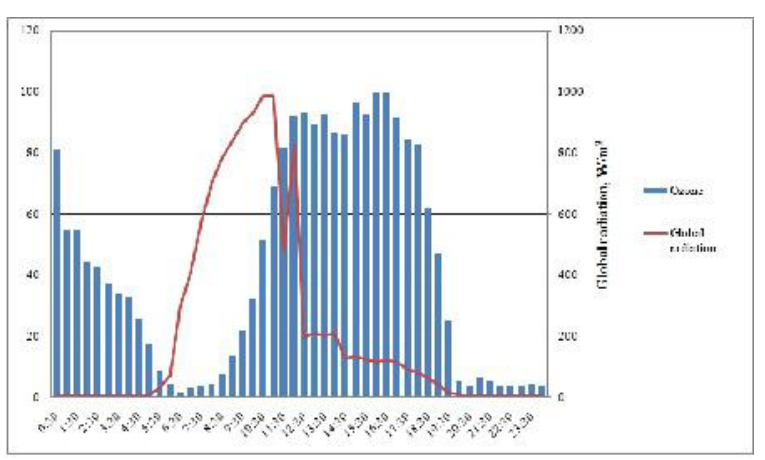

Fig. 6. Ozone concentration in relation with global radiation on a sunny day

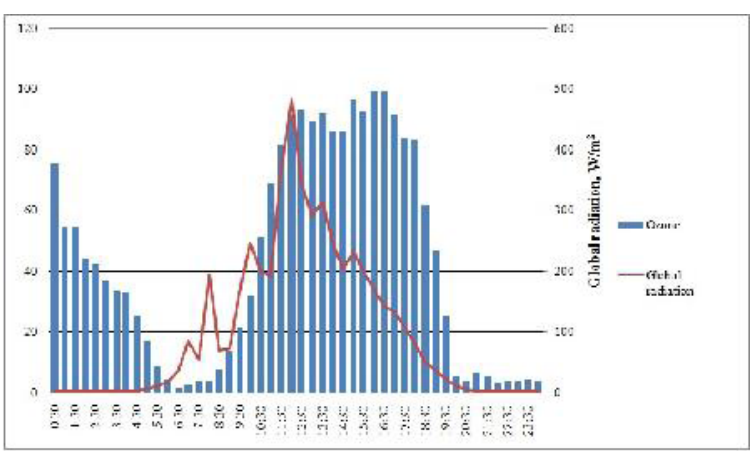

Fig. 7. Ozone concentration in relation with global radiation on a rainy/cloudy day

Table 2 and table 3 present a comparison between mean, maximum, minimum and standard deviation values for the considered days to be measured. This comparison is presented for most of the pollutants except particle matter, for this last one the values are presented separately.

Table 2. Results measured on the rainy/cloudy day, mean values, standard deviation, minimum and maximum values, $\mathrm{mg} / \mathrm{m}^{3}$

\begin{tabular}{|c|c|c|c|c|}
\hline Pollutant & Mean & $\begin{array}{c}\text { Standard } \\
\text { deviation }\end{array}$ & Max & Min \\
\hline $\mathrm{CO}$ & 0.21 & 0.03 & 0.29 & 0.18 \\
\hline $\mathrm{NO}$ & 1.19 & 1.06 & 4.50 & 0.07 \\
\hline $\mathrm{NO}_{2}$ & 13.12 & 7.62 & 30.02 & 3.51 \\
\hline $\mathrm{NO}_{\mathbf{x}}$ & 7.83 & 4.38 & 16.55 & 1.78 \\
\hline $\mathrm{O}_{3}$ & 77.16 & 13.75 & 99.40 & 54.12 \\
\hline $\mathrm{SO}_{2}$ & 3.06 & 0.67 & 4.98 & 2.26 \\
\hline Benzene & 0.34 & 0.16 & 0.91 & 0.20 \\
\hline Ethylbenzene & 0.53 & 0.11 & 0.80 & 0.38 \\
\hline Toluene & 1.58 & 0.72 & 3.46 & 0.87 \\
\hline mp-Xylene & 1.94 & 0.39 & 2.83 & 1.34 \\
\hline o-Xylene & 0.55 & 0.10 & 0.79 & 0.40 \\
\hline
\end{tabular}

Table 3. Results measured on the sunny day, mean values, standard deviation, minimum and maximum values, $\mathrm{mg} / \mathrm{m}^{3}$

\begin{tabular}{|c|c|c|c|c|}
\hline Pollutant & Mean & $\begin{array}{c}\text { Standard } \\
\text { deviation }\end{array}$ & Max & Min \\
\hline $\mathrm{CO}$ & 0.24 & 0.05 & 0.39 & 0.18 \\
\hline $\mathrm{NO}$ & 2.42 & 4.13 & 18.33 & 0.00 \\
\hline $\mathrm{NO}_{2}$ & 17.95 & 11.72 & 44.56 & 5.02 \\
\hline $\mathrm{NO}_{\mathrm{x}}$ & 11.31 & 8.76 & 38.00 & 2.55 \\
\hline $\mathrm{O}_{3}$ & 73.57 & 28.75 & 114.77 & 24.92 \\
\hline $\mathrm{SO}_{2}$ & 3.49 & 2.86 & 18.70 & 2.50 \\
\hline $\mathrm{Benzene}$ & 0.46 & 0.25 & 1.10 & 0.20 \\
\hline Ethylbenzene & 0.67 & 0.16 & 1.06 & 0.47 \\
\hline Toluene & 1.95 & 0.83 & 3.84 & 1.06 \\
\hline mp-Xylene & 2.52 & 0.57 & 3.81 & 1.66 \\
\hline o-Xylene & 0.69 & 0.17 & 1.09 & 0.42 \\
\hline
\end{tabular}


If for VOCs there is no significant influence of the rain because of their insolubility in rain water, for particle matter it is a big difference, concerning outdoor concentrations (because the particles are mechanically "washed" in the atmosphere). In figure 8 for particle matter $\mathrm{PM}_{2,5}$ and $\mathrm{PM}_{10}$ we notice a decrese of $88 \%$ for $\mathrm{PM}_{10}$ and $74,1 \%$ for $\mathrm{PM}_{2,5}$. The daily concentrations for PM10 according to Directive $50 / 2008 / \mathrm{EC}$ is $50 \mu \mathrm{g} / \mathrm{m}^{3}$, so the $93 \mu \mathrm{g} / \mathrm{m}^{3}$ value measured is almost double the limit. The particulate pollution in Bucharest is of great interest as there are many such days with concentrations that are higher than the limits. Particles pollution has been incriminated in cardiovascular and respiratory diseases, as well in autoimmune diseases [19, 20], high level of particles pollutin beeing so of great concern.

Particles $\mathrm{PM}_{2.5}$ and ozone are considered to be the most dangerous air pollutants for human health [13], and our measurements revealed higher values than the limts for both of them. Further on, the experimental campaign shall be carried out in more "hotspots" from Bucharest and for longer period of time, giving a wide range of scenarious to be studied.

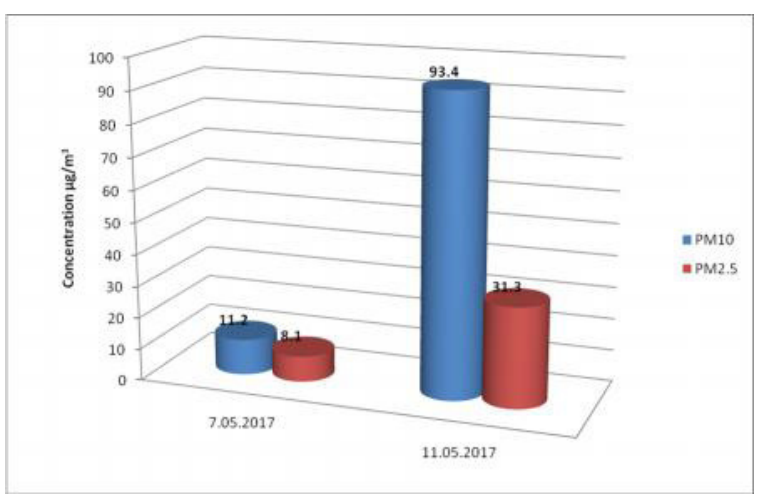

Fig. 8. Particle concentration $\mathrm{PM}_{2,5}$ and $\mathrm{PM}_{10}$

\section{Conclusions}

Traffic in Bucharest is increasing like in any other big city in the world. It is very important to have continuously measuring data to establish the pollutants that are interesting to be monitored and also to find a way to decrease the peak concentrations. Benzene and dust are two key pollutants that should be monitored in different places, as many as possible, because of their influence over the human health.

The study should have as perspectives a full year monitoring to be able to compare sunny and winter months, in different places with different pollution levels.

The novelty of this study is a start in pollutant monitoring in a highly polluted city like Bucharest using a new model of portable emission measurement system (PEM). First the pollution levels are measured, then as a perspective we should find methods cu decrease traffic related pollution levels found outdoors.

\section{References}

1. Delfino, R.J., Gong, H., Linn, W.S., Hu, Y., Pellizzari, E.D., Respiratory symptoms and peak expiratory flow in children with asthma in relation to volatile organic compounds in exhaled breath and ambient air. J. Expo. Anal. Environ. Epidemiol. 13 (5), 348-363, (2003).

2. Watson, T., Environment: breathing trouble. Nature. 513, s14-s15, (2014).

3. Wu, J., Wilhelm, M., Chung, J., Ritz, B., Comparing exposure assessment methods for traffic-related air pollution in an adverse pregnancy outcome study. Environ. Res. 111, 685-692, (2011).

4. Batterman, S., Jia, C., Hatzivasilis, G., Migration of volatile organic compounds from attached garages to residences: a major exposure source. Environ. Res. 104, 224-240, (2007).

5. L. Popescu, K.Limam - Particle Penetration Research Through Buildings Cracks - HVAC\&R Research volum 18, Issue 3, pages:312-322, DOI: 10.1080/10789669.2011.610686, ISSN: $1078-9669$ print / 1938-5587 online, (2012).

6. Edwards, P.M., et al., High winter ozone pollution from carbonyl photolysis in an oil and gas basin. Nature. 514, 351-354, 2014.

7. Snyder, R., Leukemia and benzene. Int. J. Environ. Res. Public Health. 9, 2875-2893, (2012).

8. IARC International Agency for Research on Cancer, Working Group on the Evaluation of Carcinogenic Risks to Humans. Monogr. Eval. Carcinog. Risks Hum. 45, 1-322, (1989).

9. Fustinoni, S., Bollati, V., Bertazzi, P.A., Modificazioni epigenetiche nell'esposizione a basse dosi di benzene. G. Ital. Med. Lav. Ergon. 35 (4), 263-267, (2013).

10. Bais, F.Y., Woodruff, T.J., Spear, R.C., Mechanism of benzene carcinogenesis: Application of a physiological model of benzene pharmacokinetics and metabolism. Toxicol Lett. 56, 283-298, (1991).

11. Han, X., Naeher, L.P., A review of traffic-related air pollution exposure assessment studies in the developing world. Environment International. 32, 106-120, (2006).

12. Popescu, R.S., Blondeau, P., Jouandon, E., Costes, J.C., Fanlo, J.L., Elemental modeling of adsorption filter efficiency for indoor air quality applications. Building and Environment. 66, 11-22, (2013).

13. Edwards, P.M., et al., High winter ozone pollution from carbonyl photolysis in an oil and gas basin. Nature. 514, 351-354, (2014).

14. Popescu, R.S., Blondeau, P., Jouandon, E., Colda, I., Phisically-based modeling of the influence of humidity on the efficiency of activated -carbon filters. Indoor Air 2008, (2008).

15. Safari, V, Haghigat, F, Chang, L, Blondeau, P, Popescu, R, Lakdawala, N, A systematic approach 
for evaluation of gas phase filter model, HVAC\&R Researc, pg.705-714, (2013).

16. Le Cloirec P., Les composés organiques volatils (COV) dans l'environnement. TEC \& DOC Lavoisier, Paris, 735 p, (1998).

17. Popescu, R.S., Blondeau, P., Colda, I., Modeling of an air cleaning device with activated carbon filter, Clima 2010 Conference, Antalya, Turkey, (2010).

18. M. Pascal, M. Corso, O. Chanel, C. Declercq, C. Ba daloni, G. Cesaroni, S. Henschel, K.Meister, D. Hal uza, P. Martin-Olmedo, S. Medina, Assessing the public health impacts of urban air pollution in 25 European cities: Results of the Aphekom project, Sci. Total Environ., 449 , , pp. 390-400, (2013).

19. Dean E. Schraufnagel, John R. Balmes, Clayton T. Cowl, Sara De Matteis, Soon-Hee Jung, Kevin Mortimer, Rogelio Perez-Padilla, Mary B. Rice, Horacio Riojas-Rodriguez, Akshay Sood, George D. Thurston, Teresa To, Anessa Vanker, Donald J. Wuebbles, Air Pollution and Noncommunicable Diseases: A Review by the Forum of International Respiratory Societies' Environmental Committee, Part 1: The Damaging Effects of Air Pollution, Chest, Volume 155, Issue 2, February 2019, Pages 417-426, (2019).

20. Johanna Sigaux, Jérôme Biton, Emma André, Luca Semerano, Marie-Christophe Boissier, La pollution atmosphérique comme facteur déterminant de la polyarthrite rhumatoïde, Revue du Rhumatisme, Volume 85, Issue 6, December 2018, Pages 529535, (2018). 